\title{
Creation of grades of potato with color marc of tubers
}

\author{
A. Bondarchuk, \\ corresponding member of the NAAS, Doctor of Agricultural Sciences \\ N. Furdyha, \\ L. Cherednychenko \\ Candidates of Agricultural Sciences \\ Institute for Potato Research NAAS
}

The purpose. To discus basic economic characteristics of samples of potato with colored marc of tubers, genetic supervisory control, and also practical side of creation of these forms using different methods of selection. Methods. Sexual hybridization, autogamy and selection. Conventional field, laboratory probes. Results. Dietary, special grades of potato with colored marc of tubers with the heightened content of antioxidizing agents are created. Grades are suitable for use as natural colouring agent of food stuffs and for ornamental decor of dishes. Conclusions. Perspectives of use of method of sexual hybridization for deriving forms with red and pink marc of tubers of potato up to $27,6 \%, 30,3 \%$ - with violet is determined. Autogamy of parent forms with violet marc as method is more perspective for plucking out great many of offsprings $(63 \%)$ with dark blue and violet marc of tubers of potato.

Key words: potato, selection, genes of supervisory control, hybrids, genotypes, red and violet marc of tubers, anti-oxidizing agents.

Potato is consumed by more than 3 billion inhabitants of the planet and grown in 150 countries of the world. Its cultivation range extends from polar Finland to the highlands of Ecuador and Kenya. According to the forecast, the growth of world production of this crop by 2020 will have been $40 \%$. With a particularly high rate from 1990 to 1999, its production has increased in India, China, Asia and Africa, where about 30\% of the world's harvest is obtained. [1].

In Ukraine, potato has a large and versatile value, it is used as a food, technical and feed crop. Its tubers contain about $25 \%$ of dry matter, in particular: starch - $12-22 \%$; protein - 1, 4-3 and ashy substances - 0.8-1\%. Their composition includes various vitamins (C, B, PP, K) and carotenoids [2, 3]. It is a product rich in calories, carbohydrates and vitamins. However, for human health, the importance and a range of potato varieties is significant.

Nowadays, owing to the genetic variety of potatoes in the world, a new direction in this crop selection is developing - the creation of dietary, special varieties for maintenance and improvement of human health and prevention of diseases [4]. Environmental pollution, malnutrition and stress are the main causes of a large number of free radicals. They, in turn, are byproducts of oxidation and can damage cellular membranes and DNA of cells, which can cause cancer, arthrosis, immune disorders and accelerated aging. It is therefore important that the diet contains a sufficient amount of antioxidants - substances that can protect a human body from the carcinogenic action of free radicals [5].

The sources of antioxidants are the fruits of tomatoes, table beets, broccoli cabbage, green vegetables. They contain pigments: $\beta$-carotene (orange) and lycopene (red), as well as ascorbic acid and vitamins. But now you can add another one to these traditional vegetables - potatoes with red, blue or violet pulp as a new source of antioxidants in the human diet [4].

According to the research data, potatoes with coloured pulp contain such antioxidants as zeaxanthin and lutein 4 times more than in tubers with white or yellow pulp. The antioxidant capacity of tubers with violet pulp is 6-7 times higher than that with white or yellow pulp and even larger than in carrots, onions, white pepper [6]. Owing to this property of potatoes with coloured pulp it is possible to enhance human health. 
Nowadays, in many countries, potatoes with coloured pulp are in high demand in restaurants, as well as among gardeners-lovers who grow unusual exotic crops, in particular, potatoes with coloured pulp of tubers. In the USA, potato processing plants have already been producing products from coloured potatoes (salads, chips). The greatest popularity belongs to the following varieties: Kongo, Baue Hindelblank, All Blue, Red Pearl, Parple Peruvian, Alaska Sweetheart, Cranberry Ped [4].

Tubers, rich in anthocyanin pigments, retain colour even after heat treatment: they can be fried, used for making mashed potatoes and other dishes. It is the anthocyanins that provide an intense violet coloration of eggplant, dark grapes, blackberries and blueberries. The pigment is believed to be a potent antioxidant and heals the circulatory system. Doctors have proved that it is the consumption of potato tubers with a rich violet and red colour of the pulp that significantly reduces blood sugar level, which is very important for patients with diabetes mellitus.

In addition to the properties of traditional potatoes, the colour potato has a number of other benefits. So, Gogu Valley (with red-pink peel and white pulp), Juice Valley (with raspberry peel and white pulp), Purple Valley (with violet peel and melange pulp) are consumed in raw condition, and their juice has an antibacterial property. It is drunk when people have diseases of the stomach and intestinal canal, and also used for soap production. Golden Valley potato (with light brown peel and light yellow pulp, Dasom Valley (with light brown peel and white pulp) and Bora Valley (with completely dark violet tubers) are recommended for people with poor digestion or overweight [5].

It has been established that some types of potatoes with red pulp can be successfully used as raw material for the production of food colorants.

Dishes made of coloured potatoes are the same as with potatoes with white, cream or yellow pulp. Young multicoloured potatoes are ideal for cooking, steaming, roasting and baking. You can bake potato pancakes, croquettes and crispbreads. To prevent the tubers from discolouring during cooking, you should cook them for 15-20 minutes in salted water. For salads it is better to boil coloured potatoes in their jackets. Blue or red mashed potatoes, potato fries, chips, potato pancakes, as well as various salads prepared on the basis of coloured potatoes look exotic.

At the beginning of the XXth century R. Salaman [7] established 3 independent factors of tubers' coloration: R-gene - for red coloration, P - for blue one and D - for white one. PD genotypes are blue, RD ones are red. Later he found E-gene, which controls only the colour of the eyes.

T.V. Asieieva and N.V. Nikolaieva thoroughly studied this issue [8, 9]. They found that the coloration of tubers and flowers determined the genes of the basis and manifestation. The genes of the basis are $\mathrm{P}$ and $\mathrm{R}$, which control the anthocyanin coloration of all parts of the plant, and only in the presence of the genes of the manifestation: $\mathrm{D}$ for tubers, $\mathrm{E}$ for eyes, $\mathrm{F}$ and $\mathrm{S}$ for flowers. So, the coloration of the tubers is determined by the following genes: RD - red and violet tubers with uncoloured eyes (Romano, Serpanok, Bella Rossa), RE red and violet tubers with coloured eyes (Svitanok Kyivskyi, Nadiina, Dovira), PD - blue and violet tubers with uncoloured eyes (Volynska synia - UMO 101170, dark violet - UMO 101155), PE - blue and violet tubers with coloured eyes (Tsyhanka - UMO 101065, Syniehlazka - UMO 100503) [10].

According to Ch. Brown [6], the creation of hybrids with high content of antioxidants and carotenoids is not a difficult task for the breeder. This can be achieved through interspecific hybridization, if the source material is successfully selected. He established that in the case of use of genotypes with red pulp of tubers on both sides as parental forms, up to $24 \%$ of seedlings with red pulp grew. During the breeding of genomes with red and white pulp, the number of seedlings does not exceed $4 \%$.

The genetic system that controls the coloration of the tubers was discovered in the 1950s [11] and confirmed later $[12,13]$. Scientists have experimentally proved that all oligogenes that control the coloration of potato tubers belong to the same genome.

The only $\mathrm{R}$ gene controls the red pigment and is located in the $2^{\text {nd }}$ chromosome, the synthesis of blue pigment controls $\mathrm{P}$ genome, located in the $11^{\text {th }}$ chromosome.

Pf oligogene determines the concentration of violet pigment of peel and pulp. Ch. Brown established that for the creation of hybrids with the desired coloration of the pulp of the tubers, tetraploid forms of South American 
cultural species with anthocyanin coloration of the pulp and peel and $S$. tuberosum breeding varieties were needed [6].

Research objective - to highlight the main economic characteristics of potato samples with coloured pulp of tubers, genetic control of this phenomenon, as well as practical side of creating these forms using different breeding methods.

Methods of the research - sexual hybridization, self-pollination and selection. Conventional field, laboratory studies.

Research results. At the Institute for Potato Studies of NAAS, the study on the creation of forms with coloured pulp of the tubers was started at the end of the first decade of the beginning of the XXI ${ }^{\text {st }}$ century. A precondition was the potato genetic pool of Ukraine, which at that time consisted of 2904 samples: wild and cultural species, hybrids, backcrosses, dihaploids, local forms, varieties of domestic and foreign breeding [14] .

In 2008, the laboratory of the source material carried out 7 variants of crossing, of which 3 were found to be successful. 300 buds were sprayed and 1623 hybrid seeds were obtained.

The result of hybridization depended on the components of crossing. So, the number of seeds in one berry was 52 pcs in the combination with the participation of the pollinator of Dovira and up to 67.9-97.7 pcs in combinations with the participation of Tyras and Santarka varieties.

The number of seeds per sprayed flower varied from $1.3 \mathrm{pcs}$ in the combination with the participation of Dovira variety up to 16 pcs - Santarka variety. In general hybridization managed to attract two early (Tyras, Santarka) and one mid-ripening variety (Dovira). With the participation of Rocco, Zheran, Bella Rossa varieties, the hybrid seed failed to be obtained.

To evaluate the first hybrid generation, offspring of three hybrid combinations of 300 seeds were planted with the participation of Santarka, Tyras; 156 - with Dovira variety and one population from self-pollination of UM 0101117 form (350 pcs of seeds). The seed obtained from crossing significantly differed compared to the material from F2 UM 0101117 by similarity. Its viability in the hybrid material was $38.6-93.6 \%$, from selfpollination $-37 \%$. However, in order to determine the patterns of inheritance of selectively valuable features, in particular pulp colour, the volume of the material was sufficient.

Among the hybrid populations, the largest number of genotypes with violet coloration of pulp was defined involving UM $0101117 /$ Tyras- 64 pcs., or $30.3 \%$. In combinations of UM 0101117 /Dovira and UM $101117 /$ Santarka there were 22 plants -15 and $19 \%$ respectively. As for the material from $F_{2}$ UM 0101117 , the proportion of such genotypes was $63 \%$ (82 pcs), indicating the promising use of this method for obtaining forms with violet and blue coloration of tuber pulp.

As for the coloration of pulp in red and pink, the advantage of using Santarka variety as a pollinator has been established, since $27.6 \%$ or 32 genotypes with this indicator have grown with its participation. We assume that this is the reason for the complementary interaction of $P, R, D$ genes, responsible for the colour, in particular, of the tubers. In the remaining combinations, this feature was lower and amounted to 29\% (UM 0101117 / Tyras) and 8\% (UM 101117/Dovira).

The number of plants with red and pink coloration of pulp among the material from self-pollination of UM 0101117 sample was $16 \%$, which is quite low compared to hybrid combinations.

Subsequently, these forms were studied according to other economically valuable features, in particular, by the level of productivity, starch content, suitability for potato products' processing and resistance to abiotic and biotic factors.

As you know, one of the most important features of hybrids, potato varieties is productivity. The results of the analysis of combinations involving UM 0101117 as a female parent and pollinizers of Santarka, Tyras indicate that 208p/20, 2084/1, 209 level of the manifestation of the feature was a bit lower at the level of Yavir standard variety in the remaining samples 208dp/1, 208qp/5, 208фp/11, 208ч/12, 208ч/17, 208ч/20, 209ч/2, 209ч/11 and 209ч/14.

In addition to a fairly high level of productivity, the intensity of the coloration of tuber pulp of the selected forms was also quite high. 
Thus, it has been proved that it is possible to select among the processed material the forms with high productivity. In addition, it is likely that the heteroallelism of the polygens of control of the feature has led to the growth of high-yield hybrids, in combination with the coloured pulp of tubers, which is higher by value than that of the standard varieties.

There is a general opinion that potato yields mainly depend on the number of tubers under the bush and their average mass. It has been established that both features are passed on to the descendants, but the effectiveness of their genetic control depends on the characteristics of the original forms in the crossing.

According to the average number obtained in 2010-2011 there were 3 hybrids that had 14 or more tubers in the bush, which is not much more than that of Svitanok Kyivsky that is the best of the standard variety (13 pcs/bush). The analysis of the distribution on the basis of this characteristic indicates that the smallest manifestation of the feature (6 pcs) was found in the samples $2084 / 10$ (UM0101117/Santarka), 209dp/8, 209p/16 (UM0101117/Tyras), although it was higher than in the standard variety Serpanok.

The possibility of combining multituberous feature with other economically valuable features has been established. In particular, this relates to the form $178 \mathrm{~d} / 5$ in combination with multituberous feature - 11 pcs, high marketability $-97.2 \%$ and the number of commercial tubers - 10 pcs.

Yield capacity is the most important feature of varieties, the result of the combination of the action of the number of tubers and their mass. A significant influence of external factors on the average mass of the commercial tubers has been established. Thus, in 2010, the indicators were lower compared to 2011. It was established that the best on the basis of the feature was the genotype $209 \mathrm{~d} / 14-91.7 \mathrm{~g}$. The samples $178 \mathrm{p} / 5$ $-87.3 \mathrm{~g} ; 208 \mathrm{dp} / 5-81.3 ; 209 \mathrm{~d} / 16-86.3 ; 2094 / 2-85.5 \mathrm{~g}$ were of a bit lower, but also of great importance; which exceeds the individual standard varieties.

Marketability is an indicator that characterizes the quality of the harvest. The analysis of the given material shows a significant difference in distribution. It should be noted that only two forms (178 $4 / 5$ and 209dp/15) had a manifestation of the feature below $90 \%$, which is at the level of the standard variety Svitanok Kyivskyi. The form 208dp/5 should be distinguished with the participation of UMO 101117/Santarka, the manifestation of which was $98.2 \%$, which is the highest among the used material. Significant influence of pollinators has not been established.

$50 \%$ of the used material is characterized by high and increased content of starch. A small proportion of hybrids was with very low content of starch (12\% or less). Only in one population (2094/7) the average value was $22.4 \%$, which exceeded the best in this respect standard variety Svitanok Kyivskyi (19.8\%). As for the rest of the material, it was at the level of standard varieties.

According to the results base on field trials conducted many years, hybrids under the varietal names Solokha and Khortytsia were transferred on infectious backgrounds to the State test for registration in the Register of plant varieties common within the territory of Ukraine.

Solokha variety is a mid-ripening, table, dietary variety. Starch content amounts to $19.2 \%$, yield capacity makes $38 \mathrm{t} / \mathrm{ha}$ at the end of growing season. Tubers are dark violet, rounded and egg shaped, with dark violet pulp and white flowers. The number of tubers under the bush is $12-15$ pcs. It is resistant to cancer, potato nematode, common potato scab. It has an intense blue coloration of pulp and it is very delicious in fried form. It is recommended for growing in Polissia and forest-steppe zone.

Khortytsia variety is a mid-ripening, table, dietary variety. Yield capacity makes $35-37 \mathrm{t} / \mathrm{ha}$ at the end of the growing season. Starch content amounts to $19 \%$, taste is good (8.4 points). It is resistant to potato nematodes, late blight and common potato scab. Tubers are red, elongated, with red pulp and white flowers. It is recommended for growing in the Polissia and forest-steppe zone.

Features of varieties are the following: they have a high content of antioxidants - $\beta$-carotene, lycopene, zeaxanthin. Owing to these features it can be used as a dietary product and a prophylactic remedy to improve the functioning and treatment of digestive and circulatory systems and to strengthen immunity. It is suitable for use as a natural dye for food and it can be used to decorate dishes (salads, French fries, mashed potato). 


\section{Conclusions}

According to the results of the study of the samples that were characterized by intense coloration of tuber pulp, high indicators of such economically valuable features as productivity and its components have been established. The selected hybrids, which exceeded the best standard varieties based on the features, were further transferred to the breeding laboratory in the breeding nursery for a more detailed study.

\section{References}

1. Zandastra $H$. Retrospoct and future prospects of potato research and development in the world/H. Zandastra//Clod. Conf. on Potato. - New Delhi, 1999. - 8 p.

2. A.A. Kuchko Potato physiology and biochemistry / A.A. Kuchko, M.Yu. Vlasenko, V.M. Mytsko. - K.: Dovira, 1998. - 336p.

3. K.Z. Budin Catalog of the world collection of VIR. Mexico potato types and their significance for breeding / K.Z. Budin, L.E. Gorbatenko, L.M. Turuleva. - L., 1989. - Issue. 439. - 88 p.

4. S.D. Kiru Genetic resources of Potatoes for new directions of breeding/S.D. Kiru // Scientific support and innovative development of potato growing: materials of research-to-practice conference and coordination meetings. - M., 2008. - P. 49-56.

5. The inheritance of athocyanin pigmentation in potato (Solanum tuberosum L.) and mapping of tuber skin colour uning RELP Hereditu/Van Ecк H. Jacobs. P.M.M. Van den Berg, W.J. Stiekema, E. Jacobsen. 1994. - V. 73. P. 410-421.

6. Breeding Studies in Potatoes Containing High Concentrations of Anthocyanins/C.R. Brown, R. Wrolstad, R. Durst et al.//Amer. J. of Potato Res. - 2003. - V. 80. - P. 241-250.

7. Salaman R.N. Male-sterilitu in potatoes/R.N.Salaman//J. Linn. Soc. -London, 1910._P. 177.

8. T.V. Aseeva Genetic nature of the coloration of tubers, sprouts and flowers in potatoes /T.V. Aseeva, N.V. Nikolaeva//Works of Potato Research Institute. - 1935. - Issue. 9. - P. 107.

9. T.V. Aseeva Potato genetics /T.V. Aseeva // Potato. - M., 1937. - P. 139-165.

10. L.I. Kostina Potato/L.I. Kostina, L.V. Koroleva// Identified plant gene pool and breeding: works dedicated the 110th anniversary of Vavilov Institute of Plant Industry. - St. Petersburg., 2005. - P. 881-885.

11. Dodds K.S. The inheritance of coloun in diploid potato: types of anthocyanidins and their genetic loci/K.S. Dodds, D.H. Long//Genetics, 1955. - V. 53. - P. 136-149.

12. De Long H. Inheritance of anthocyanin pigmentation in the cultivated potato: a critical review//Amercan Potato J., 1991. V. 64. -P. 585-593.

13. The inheritance of athocyanin pigmentation in potato (Solanum tuberosum L.) and mapping of tuber skin colour uning RFLP Hereditu/Van Eck H.J.J. Jacobs, P.M.M. Van den Berg, W.J. Stiekema, E. Jacobsen. - 1994. - V. 73. - P. 410-421.

14. M.M Furdyha New directions for potato breeding /M.M Furdyha //Potato growing of Ukraine. - 2010. No. 1-2 (18-19). - P. 4-8. 